\title{
Atypical and anaplastic meningiomas in a public hospital in São Paulo State, Brazil
}

\author{
Meningiomas atípicos e anaplásicos em um hospital público de São Paulo, Brasil \\ Benedicto Oscar Colli', Carlos Gilberto Carlotti Junior', João Alberto Assirati Junior', Vicente de Paulo \\ Martins Coelho Junior' , Luciano Neder²
}

\begin{abstract}
Atypical/anaplastic (World Health Organization (WHO) grades II and III) are less common and have poorer outcomes than benign meningiomas. This study aimed to analyze the outcome of patients with these tumors. Method: Overall/recurrence-free survivals (RFS) and the Karnofsky Performance Scale of 52 patients with grades II (42) and III (9) meningiomas surgically treated were analyzed (uni/multivariate analysis). Results: Total/subtotal resections were $60.8 \% / 35.3 \%$. Patients $<60$ years-old and grade II tumors had longer survival. Grade II tumors, total resection and de novo meningioma had better RFS (univariate analysis). Patients $>60$ years-old, de novo meningioma and radiotherapy had longer survival and patients <60 years-old and with grade II tumors had longer RFS (multivariate analysis). Recurrence rate was $51 \%$ (39.2\% Grade II and 66.7\% Grade III). Operative mortality was 1.9\%. Conclusion: Age <60 years-old, grade II tumors and de novo meningiomas were the main predictors for better prognosis among patients with grades II and III meningiomas.
\end{abstract}

Keywords: atypical and anaplastic meningiomas, surgical treatment, extent of resection, survival curves, recurrence survival curves.

\section{RESUMO}

Meningiomas atipicos/anaplásticos (graus II e III da World Health Organization (WHO)) são menos comuns e tem prognóstico pior que os benignos. Este estudo visa analisar o prognóstico de pacientes com estes tumores. Método: Sobrevida/sobrevida livre de doença (SLD) e índice de Karnofsky de 52 pacientes com meningiomas graus II (42) e III (9) tratados cirurgicamente foram avaliados (análises uni/multivariada). Resultados: Pacientes $<60$ anos e com tumores grau II tiveram sobrevida mais longa. Tumores grau II , ressecção total e meningioma de novo tiveram melhor SLD (análise univariada). Pacientes $>60$ anos, meningioma de novo e radioterapia tiveram sobrevida mais longa e, pacientes $<60$ anos e com tumores grau II tiveram SLD mais longa (análise multivariada). Recidiva ocorreu em 51\% (39.2\% Graus II e 66,7\% Graus III). A mortalidade operatória foi 1,9\%. Conclusão: Idade <60 anos, meningiomas grau II e de novo foram preditores de melhor prognóstico entre pacientes com meningiomas graus II/ III.

Palavras-chave: meningiomas atípicos e anaplásicos, tratamento cirúrgico, extensão da ressecção, curvas de sobrevida, curvas de sobrevida livre de doença.

Meningiomas constitute 13 to $26 \%$ of all intracranial tumors ${ }^{1,2,3,4,5}$ Cushing and Eisenhardt ${ }^{4}$, described meningiomas with more aggressive histopathological characteristics and worst clinical prognosis and classified them as malignant forms. Later, D A Arrigo et al. ${ }^{6}$ described another subgroup of meningiomas, atypical, characterized by slower growth, but, with high recurrence rates. These tumors are included in grades II and grade III of the World Health Organization (WHO) classification ${ }^{1,7}$; they can originate from malignant progression of a benign meningioma that accumulates mutations.
Atypical and anaplastic meningiomas account for $3.0-7.2 \%$ and 0.4-3.7\% $\%^{1,3,5,8,9}$, respectively, of intracranial meningiomas. Female predominance is less marked and there is even male predominance among them ${ }^{2,8,9,10}$, and they are more common in the cerebral convexities ${ }^{2,9,10}$. Although surgery is considered the primary treatment for these forms ${ }^{10,11}$, the high recurrence rates requires other therapeutic modalities, such as radiation therapy, and chemotherapy. This study aimed to identify factors that influence the clinical outcome of patients with atypical and anaplastic meningiomas treated at our institution.

\footnotetext{
${ }^{1}$ Universidade de São Paulo, Faculdade de Medicina de Ribeirão Preto, Hospital das Clínicas, Departamento de Neurocirurgia, Ribeirao Preto SP, Brazil; 2Universidade de São Paulo, Faculdade de Medicina de Ribeirão Preto, Hospital das Clínicas, Departamento de Patologia, Ribeirao Preto SP, Brazil. Correspondence: Benedicto Oscar Colli; HCFMRP-USP, Divisão de Neurocirurgia, Departamento de Cirurgia, Campus Universitário USP; $14048-900$ Ribeirão Preto SP, Brasil; E-mail: bocolli@fmrp.usp.br

Conflict of interest: There is no conflict of interest to declare.

Received 05 November 2014; Received in final form 22 April 2015; Accepted 13 May 2015.
} 


\section{METHOD}

\section{Patient population}

This study was a retrospective review of the medical records of 52 consecutive patients with WHO Grade II or Grade III meningiomas who underwent surgery from 1984 to 2013 at the Division of Neurosurgery, Department of Surgery, Hospital das Clinicas, Ribeirão Preto Medical School - University of São Paulo (HCFMRP-USP). The study was approved by the Ethics in Research Committee of the HCFMRP-USP (No 736.988, 21/07/14). These patients comprised $10 \%$ (52 of 522) of patients with intracranial meningioma treated in the same period and $75 \%$ of the cases were operated on by the senior author (BOC). Diagnosis was performed using CT and/or MR imaging of the head. Tumors were more frequently located in the parasagittal region and on the convexity (Table 1). Tumors were classified according to the 2007 histopathological WHO criteria $^{1,7}$, (slides of patients operated in the first years were reviewed). Forty-three (82.7\%) patients had Grade II meningiomas (37 atypical, 3 clear cell and 3 chordoid subtypes) and nine (17.3\%) had Grade III (7 anaplastic, 1 papillary and 1 rhabdoid) meningiomas. Nine (17.3\%) patients had multiple meningiomas (six with two, one with three and two with five tumors). One patient with multiple meningiomas had neurofibromatosis type 2. Forty-three $(82.7 \%)$ were de novo meningiomas and nine (17.3\%) were tumors with malignant progression. Among the later, four patients progressed from grade I to atypical grade II $(0.8 \%$ of grade I meningiomas) after recurrence (at $39,45,84$, and 195 months); the earlier, first biopsies of these 4 patients had focal areas of atypia not sufficient to be considered grade II. Two patients with grade I ( $0.4 \%$ of grade I meningiomas) and three with atypical grade II tumors progressed (7\% of grades II meningiomas) to grade III after recurrence (at 4, 5, 12, and 26 months).

\section{Clinical findings}

The most important demographic characteristics of patients are presented in Table 2 and Figure 1. There was a female predominance for all patients (1.3:1) and for patients with Grade II (1.5:1), and a slight male predominance among patients with Grade III tumors (0.8:1). The sex distribution was similar for patients with Grade II and Grade III tumors ( $\mathrm{p}=0.8732$ ).

Age ranged from 16 to 89 years old ( mean $=54.77 \pm 15.91)$. Patients with Grade II were significantly younger than were patients with Grade III tumors (means: 53.86 vs 75.22 months, $\mathrm{p}=0.0015$, Kruskal-Wallis test, with Dunn's multiple comparison test); the same was observed for females (means: 51.96 vs 73.75 years, $p=0.0007$, Kruskal-Wallis test, with Dunn's multiple comparison test) and for males (means: 47.56 vs 76.40 years, $\mathrm{p}=0.0034$, Kruskal-Wallis test, with Dunn's multiple comparison test). Follow-up ranged from 3 to 257 months ( mean $=66.02 \pm 59.96 ;$ median $=44.50$ months . .

The main clinical signs and symptoms at admission are summarized in Table 3. The most frequent were motor deficits, cranial nerve palsies and seizures.

Two male patients with grade II (atypical) meningiomas ( falcine and petrous) underwent previous whole brain radiotherapy and chemotherapy (one 27-year-old for treatment of a medulloblastoma 8 years earlier; and another 23-year-old for lymphoid leukemia twice, 14 and 3 years earlier).

\section{Management of the disease}

Surgical Treatment: Surgery was performed using microsurgical techniques, with the aims of the most extensive safe resection possible and avoidance of new or increased neurological deficits. The extent of resection was assessed macroscopically during surgery and postoperatively using CT or MR imaging 48 hours and 6 months after operation categorized as radical removal (no evidence or doubt about residual tumor in the MR image); subtotal (resection $>90 \%$ ) and partial (resection was $>90 \%$ ).

Table 1. Location of grades II and III meningiomas in 50 patients operated on.

\begin{tabular}{|c|c|c|c|c|}
\hline \multirow{2}{*}{ Location } & & \multicolumn{3}{|c|}{ WHO Histopathological Grades } \\
\hline & & Grade II & Grade III & Total \\
\hline \multirow[t]{3}{*}{ Parasagittal } & Anterior Third & 04 & & 04 \\
\hline & Middle Third & 06 & 01 & 07 \\
\hline & Posterior Third & 01 & & 01 \\
\hline \multirow[t]{3}{*}{ Convexity } & Fronto-Parietal & 02 & 02 & 02 \\
\hline & Fronto-Temporal & 01 & 02 & 03 \\
\hline & Parietal & 04 & & 04 \\
\hline \multirow[t]{2}{*}{ Sphenoid Wing } & Internal Third & 02 & & 02 \\
\hline & Middle Third & 01 & & 01 \\
\hline Diafragma Selae & & & 01 & 01 \\
\hline \multirow[t]{2}{*}{ Falx } & Anterior Third & 02 & & 02 \\
\hline & Middle Third & 01 & & 01 \\
\hline Falco-Tentorial & & 01 & & 01 \\
\hline Middle Fossa & & 02 & & 02 \\
\hline Olfactory Groove & & 02 & & 02 \\
\hline
\end{tabular}


Table 2. Summary of demographic data in 50 patients with WHO grades II and III meningiomas.

\begin{tabular}{|c|c|c|c|c|c|}
\hline Characteristic & $\begin{array}{c}\text { Grade II } \\
\text { Meningiomas atypical }\end{array}$ & $\begin{array}{c}\text { Grade II } \\
\text { Meningiomas other }\end{array}$ & $\begin{array}{c}\text { Grade II } \\
\text { Meningiomas total }\end{array}$ & $\begin{array}{c}\text { Grade III } \\
\text { Meningiomas }\end{array}$ & Total \\
\hline \multicolumn{6}{|l|}{ Sex } \\
\hline Female & 22 & 5 & 27 & 4 & 31 \\
\hline Male & 15 & 1 & 16 & 5 & 21 \\
\hline Female/male & $1.5: 1$ & $5: 1$ & $1.7: 1$ & $0.8: 1$ & $1.5: 1$ \\
\hline Age $(y r s)^{*}$ & $53.95 \pm 14.70$ & $53.33 \pm 21.32$ & $53.86 \pm 15.47$ & $75.22 \pm 7.546$ & $54.77 \pm 15.91$ \\
\hline Age range (yrs) & $17-76$ & $25-81$ & $16-81$ & $31-89$ & $16-89$ \\
\hline Female & $25-64$ & $65-68$ & $25-68$ & $69-81$ & $25-81$ \\
\hline Male & $16-62$ & $65-65$ & $16-25$ & $67-89$ & $16-89$ \\
\hline Follow-up (months)* & $66.59 \pm 59.85$ & $59.17 \pm 41.00$ & $65.23 \pm 57.56$ & $78.25 \pm 74.52$ & $69.78 \pm 74.20$ \\
\hline
\end{tabular}

* Values presented as the means \pm standard deviation.

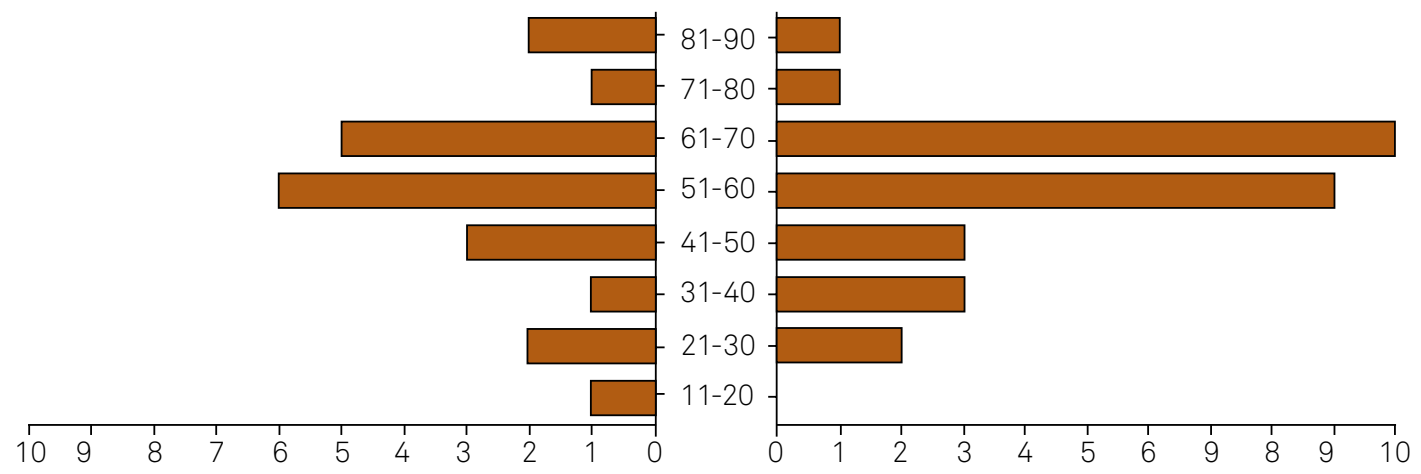

Figure 1. Age and sex distribution of WHO grades II and III meningiomas based on 50 cases treated at the Hospital das Clínicas, Ribeirão - Preto Medical School - University of São Paulo, Ribeirão Preto, São Paulo, Brazil.

Table 3. Initial signs and symptoms in 51 patients with grades II and III meningiomas.

\begin{tabular}{lccc}
\hline Histological grade & OMS II & OMS III & Total \\
\hline Motor deficit & $9(21.4 \%)$ & 0 & $9(17.7 \%)$ \\
Cranial nerve deficits & $9(21.4 \%)$ & $3(22.2 \%)$ & $12(23.5 \%)$ \\
Seizures & $8(19.1 \%)$ & $1(11.1 \%)$ & $9(17.7 \%)$ \\
Protusion of the skull & $5(11.9 \%)$ & 0 & $3(05.9 \%)$ \\
Intracranial hypertension & $4(09.5 \%)$ & $1(11.1 \%)$ & $4(07.8 \%)$ \\
Superior cortical function deficits & $3(71.4 \%)$ & 0 & $4(07.8 \%)$ \\
Headache & $3(71.4 \%)$ & $2(22.2 \%)$ & $3(05.9 \%)$ \\
Incidental & $1(02.4 \%)$ & $2(22.2 \%)$ & $5(09.8 \%)$ \\
Total & 42 & 9 & 51 \\
\hline
\end{tabular}

Twenty (36.5\%) patients (16 with Grade II and 4 with Grade III meningiomas) underwent adjuvant radiotherapy. Nineteen were submitted to external beam fractionated radiotherapy and one to conformational radiotherapy (doses: 4,500 to 6,000 cGy). Twelve patients were treated after the first surgery (all Grade II) and 8 after the first recurrence.

\section{Functional outcome}

Functional outcomes were compared between patients with histopathological Grades II vs III tumors and between atypical and other subtypes of Grade II tumors. The preoperative, postoperative (first 10 days) and the follow-up outcome were analyzed using the Karnofsky Performance Scale (KPS) for 48 patients. Patients were classified into one of three functional status categories: 1) Normal function or minimal symptoms and ability to work (KPS 80-100), 2) Independent but not able to work (KPS 70), and 3) Moderate or severe disability (KPS $<70$. For patients with tumor recurrence and clinical deterioration, the highest KPS score obtained during the follow-up evaluations was used. Two patients did not attend the 6 months follow-up and did not receive a KPS score at this time.

Survival analysis was performed using Kaplan-Mayer overall survival (censoring event: death), and recurrence-free survival (RFS) curves (censoring event: recurrence) and rates in relation to sex, age, histopathological grade, and extent of resection, use of radiation therapy, and malignant progression.

\section{Statistical analysis}

Statistical analyses was performed using the Chi-square and Fisher's exact tests to compare proportions, the KruskallWallis non-parametric test and the analysis of variance (ANOVA) to compare medians, and the log-rank test to compare overall and RFS curves using the Graph Pad PRISM (version 3.0; Graph Pad Software Inc. San Diego, CA). Multivariate analysis for selected clinical variables was performed using Cox-Regression (SPSS-Version 21.0, IBM Corporation, Armonk, NY). An $\alpha$-error probability not exceeding $5 \%$ was considered significant for two-tailed probability tests. 


\section{RESULTS}

\section{Summary of surgical treatment}

Thirty-five (67.3\%, 29 Grade II/6 Grade III) patients underwent radical tumor resection, fourteen $(26.9 \%, 10$ Grade II/4 Grade III) had subtotal and three (5.8\%, Grade II) had partial resection.

Survival: Tables 4 (univariate analysis) and 5 (multivariate analysis) presents the results of the analysis of factors evaluated for an association with the overall survival of patients with WHO grades II and III meningiomas. Patients $<60$-years-old survived longer than did patients $>60$-year-old (univariate Figure 2, and multivariate analysis), and patients with grade II tumors survived longer than did patients with grade III tumors (univariate analysis - Figure 3). Histological progression, radiotherapy and recurrence were predictors for longer survival (multivariate analysis).

Recurrence: The results of the analysis of factors that can influence the RFS of patients with WHO grades II and III meningiomas are presented in Tables 4 (univariate) and 5 (multivariate). The recurrence rates during follow-up were $50 \%$ (26/52 patients), $46.5 \%$ (20/43 patients) and $66.7 \%$ (6/9 patients), respectively, in all patients, in patients with WHO Grade II and with III meningiomas. Among patients with Grade II tumors, 16 (80\%) recurred in the first 5 years and the other $4(20 \%)$ recurred after 10 years. All six recurrences in patients with Grade III meningiomas occurred in the first 3 years.

RFS was longer for patients with grade II than with grade III meningiomas (univariate - Figure 4, and multivariate analysis), for patients who underwent total resection than with subtotal resection, for patients with de novo than in patients with malignant transformation (univariate analysis - Figures 5 and 6), and for patients $>60$-years-old (multivariate analysis).

\section{Mortality and morbidity}

One patient (grade II) died in the first postoperative month after surgery, due to pulmonary embolism. Two patients (grades II and III) died, respectively, three and two months after surgery due to pulmonary infection and $13 \mathrm{pa}-$ tients died during the follow-up period (operative mortality: 2 [3.9\%] patients; surgery related mortality: 3 [5.8\%] patients; and overall mortality: 16 [30.8\%] patients). During follow-up, nine deaths occurred due to progression of Grades II ( five patients) and III (four patients) tumors and four deaths were not related to tumor.

Transient (5 [9.6\%] patients) or permanent (6 [11.5\%] patients) neurological postoperative complications occurred in $11(21.2 \%)$ patients (10 with Grade II and one with Grade III tumors). The most frequent complication were hemiparesis in six (11.5\%) patients (four transient [75\%] and two [25\%] permanent), and cranial nerve deficits in $3(5.8 \%)$ patients (II/III/IV/VI in one; V/VII in the second; and V/VI/VII in the

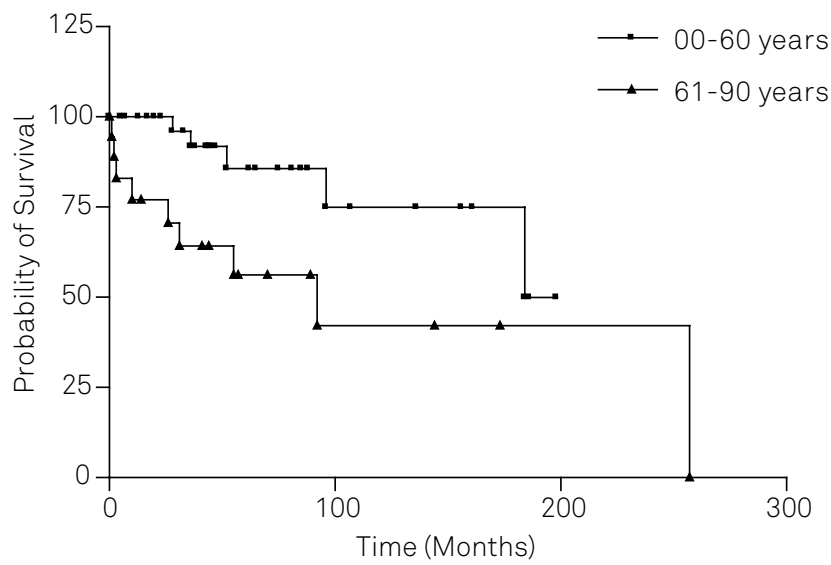

Figure 2. Survival curves for patients with WHO grades II and III according age ( $\leq 60$ years-old vs $>60$ years old). Significant difference $(p=0.0221, d f=1$, [log-rank test].

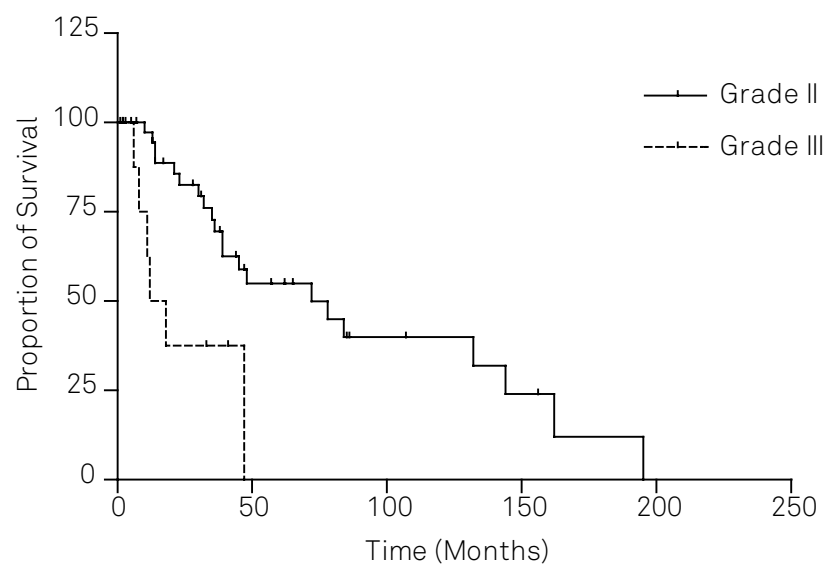

Figure 3. Survival curves for patients according WHO histological grades. Significant difference $(p=0.0034, d f=1$, log-rank test).

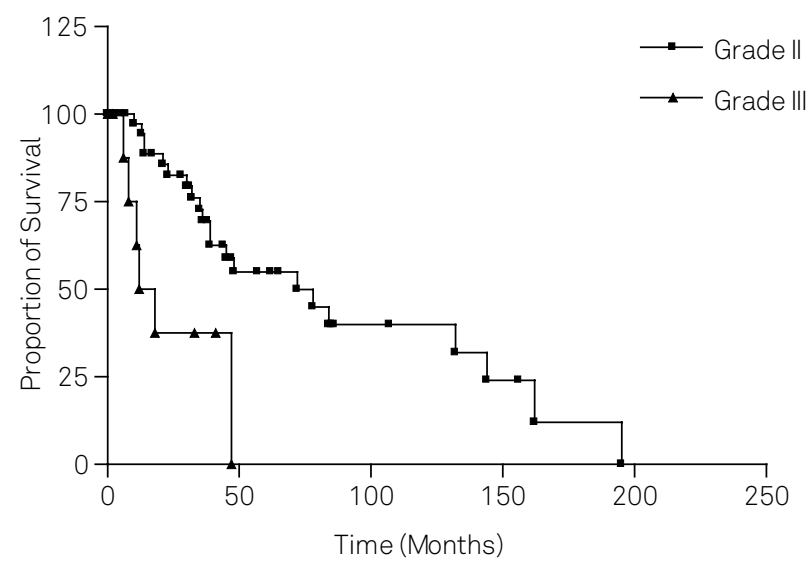

Figure 4. Recurrence-free survival curve for patients with WHO grades II and III. Significant difference $(p=0.0030$, $d f=1$, log-rank test $)$.

third patient ). Two patients had deep venous thrombosis, one of them developed pulmonary embolism. Another patient had osteomyelitis. 
Table 4. Summary of the analysis of survival curves according factors that can influence the overall survival of patients with WHO grades II and III meningiomas.

\begin{tabular}{|c|c|c|c|c|}
\hline & 5y RFE & 10y RFE & Median survival & Analysis \\
\hline \multicolumn{5}{|l|}{ Age } \\
\hline Decades of life & - & - & - & $p=0,1012$, log-rank test,$d f=7$ \\
\hline$>60$ years-old & 85.7 vs $56.2 \%$ & 75.0 vs $42.1 \%$ & - & $p=0.0212^{\star}$, log-rank test, $d f=1$ \\
\hline \multicolumn{5}{|l|}{ Sex (female vs male) } \\
\hline All patients & 73.7 vs $63.1 \%$ & 55.3 vs $47.7 \%$ & Undef vs 136.0y & $p=0.6511$, log-rank test,$d f=1$ \\
\hline Grade II & 73.0 vs $78.4 \%$ & 58.4 vs $58.8 \%$ & Undef vs Undef & $p=0.7281$, log-rank test,$d f=1$ \\
\hline Grade III & 50.0 vs $0.0 \%$ & 50.0 vs $0.0 \%$ & 147.0 vs $36.0 y$ & $p=0.3261$, log-rank test,$d f=1$ \\
\hline \multicolumn{5}{|l|}{ WHO Histopathological grade } \\
\hline G I, G I-atypical, G II-other subtype, G III) & 75.7 vs $75.1 \%$ & 51.1 vs $47.7 \%$ & - & $p=0.5823$, log-rank test,$d f=3$ \\
\hline All Patients(G II vs G III) & 85.7 vs $56.2 \%$ & 75.0 vs $42.1 \%$ & 184.0 vs $92.0 y$ & $p=0,0221^{*}$, log-rank test, $d f=1$ \\
\hline De Novo vs malignant progression & 72.9 vs $46.9 \%$ & 63.0 vs $31.3 \%$ & Undef vs 96.0y & $p=0.1955$, log-rank test, $d f=1$ \\
\hline \multicolumn{5}{|l|}{ Extent of resection (radical, subtotal) } \\
\hline Grades II and III & 82.8 vs $61.4 \%$ & 63.1 vs $40.9 \%$ & Undef vs 96.0y & $p=0.2322$, log-rank test, $d f=2$ \\
\hline Grade II & 88.4 vs $61.0 \%$ & 64.4 vs $61.0 \%$ & Undef vs Undef & $p=0.6880$, log-rank test,$d f=1$ \\
\hline Grade III & 50.0 vs $30.0 \%$ & 50.0 vs $30.0 \%$ & 111.0 vs $96.0 y$ & $p=0.6823$, log-rank test, $d f=1$ \\
\hline RT After $1^{\text {st }}$ surgery (RT vs No RT & 52.7 vs $78.6 \%$ & 52.7 vs $62.8 \%$ & 186.0y vs Undef & $p=0,6698$, log-rank test, $d f=1$ \\
\hline KPS at admittance ( $\leq 70 \mathrm{vs}>70)$ & 74.3 vs $75.8 \%$ & 37.1 vs $65.0 \%$ & 96.0 vs Undef & $p=0.5267$. log-rank test, $d f=1$ \\
\hline
\end{tabular}

RFE: recurrence-free estimate; Undef: undefined;WHO: World Health Organization; y: year; * significant difference.

Table 5. Summary of the analysis of factors that can influence the overall recurrence-free survival of patients with WHO grades II and III meningiomas.

\begin{tabular}{|c|c|c|c|c|}
\hline & 5y RFE & 10yr RFE & $\begin{array}{l}\text { Median } \\
\text { Survival }\end{array}$ & Analysis \\
\hline Recurrence/Regrowing rate Gll vs G III (46.5\% vs 66.7\%) & - & - & - & $p=0.4654$, Fisher's exact test \\
\hline \multicolumn{5}{|l|}{ Age } \\
\hline Decades of life & - & - & - & $p=0.7799$, log-rank test, $\mathrm{df}=7$ \\
\hline$>60$ years-old & 45.9 vs $53.0 \%$ & 25.5 vs $12.9 \%$ & 48.0 vs $84.0 y$ & $p=0.9469$, log-rank test, $\mathrm{df}=1$ \\
\hline \multicolumn{5}{|l|}{ WHO Histopathological grade } \\
\hline Grades (II vs III) & $55.1 \%$ vs $0.0 \%$ & 32.1 vs $0.0 \%$ & 78.0 vs $15.0 y$ & $p<0.0030 *$, log-rank test, $d f=1$ \\
\hline Atypical vs other subtypes G II & 52.1 vs $10.5 \%$ & 26.0 vs $32.5 \%$ & 72.0 vs Undef & $\mathrm{p}<0.2033$, log-rank test, $\mathrm{df}=1$ \\
\hline De Novo vs Malignant progression & 51.1 vs $0.0 \%$ & 31.8 vs $0.0 \%$ & 72.0 vs $15.0 y$ & $p=0.0010^{*}$, log-rank test,$d f=1$ \\
\hline \multicolumn{5}{|l|}{ Sex } \\
\hline All patients, & 53.7 vs $32.2 \%$ & 25.6 vs $32.2 \%$ & 72.0 vs $45.0 \%$ & $p=0.7396$, log-rank test,$d f=1$ \\
\hline Patients with grade II & 64.3 vs $32.5 \%$ & 30.6 vs $32.5 \%$ & 78.0 vs $45.0 y$ & $p=0.5612$, log-rank test, $d f=1$ \\
\hline Patients with grade III & 0.0 vs $0.0 \%$ & 0.0 vs $0.0 \%$ & 15.0 vs $29.0 y$ & $p=0.7675$, log-rank test,$d f=1$ \\
\hline \multicolumn{5}{|l|}{ Extent of resection (radical, subtotal) } \\
\hline All patients & 65.4 vs $33.0 \%$ & 46.5 vs $0.0 \%$ & - & $p=0.011 * 9$ log-rank test, $d f=1$ \\
\hline Patients with grade II & 64.8 vs $45.5 \%$ & 42.6 vs $15.4 \%$ & 132.0 vs $36.0 y$ & $p=0.2968$, log-rank test, $d f=1$ \\
\hline Patients with grade III & 0.0 vs $0.0 \%$ & 0.0 vs $0.0 \%$ & 11.5 vs $32.5 y$ & $p=0.3948$, log-rank test, $d f=1$ \\
\hline RT After $1^{\text {st }}$ surgery (RT x No RT) & 29.2 vs $57.4 \%$ & 29.2 vs $0.0 \%$ & 36.0 vs $72.0 y$ & $p=0.4895$, log-rank test, $d f=1$ \\
\hline KPS at admittance ( $\leq 70$ vs $>70)$ & 31.1 vs $54.9 \%$ & 15.6 vs $27.4 \%$ & 39.0 vs $78.0 y$ & $p=0.4719$ log-rank test, def $=1$ \\
\hline
\end{tabular}

RFE: recurrence-free estimate; Undef: undefined;WHO: World Health Organization; y: year; * significant difference.

\section{Postoperative functional outcome}

Preoperative, immediate postoperative and follow-up functional disabilities assessed by KPS are presented in Table 6. The proportions of patients in the functional categories were similar in all evaluations $(p=0.5107$ for all patients, $\mathrm{p}=0.4694$ for patients with Grade II tumors, and $\mathrm{p}=0.9056$ for patients with Grade III tumors). Preoperatively $12(27.9 \%)$ patients had KPS scores $\leq 70$, and postoperatively $14(32.6 \%)$ had similar KPS scores $(p=0.5059)$. Three
(5.9\%) patients (two with Grade II and one with Grade III) experienced postoperatively deterioration (KPS score $\leq 70$ ) and one Grade III (1.9\%) experienced improvement (KPS 280). Assessment at 6 months identified 5 additional patients (four Grade II and one Grade III) with KPS score $\leq 70$. There was no significant differences between the overall survival and RFS curves for patients with KPS score $\leq 70$ and with KPS $>70$ on admission (respectively, $p=0.5107$ and $\mathrm{p}=0.4719)$ Tables 4 and 5 . 


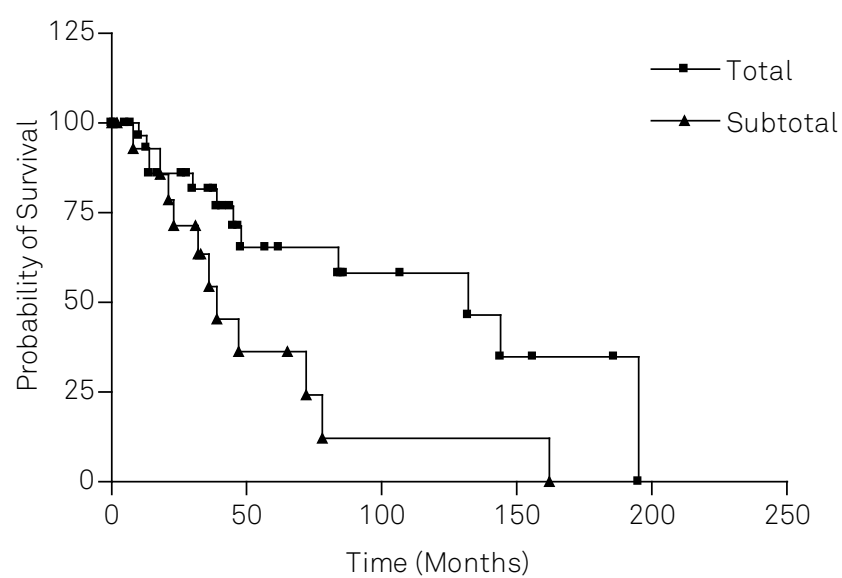

Figure 5. Recurrence-free survival curves for patients according the extent of resection. Significant difference ( $p=0.0192, \mathrm{df}=2$, log-rank-test.

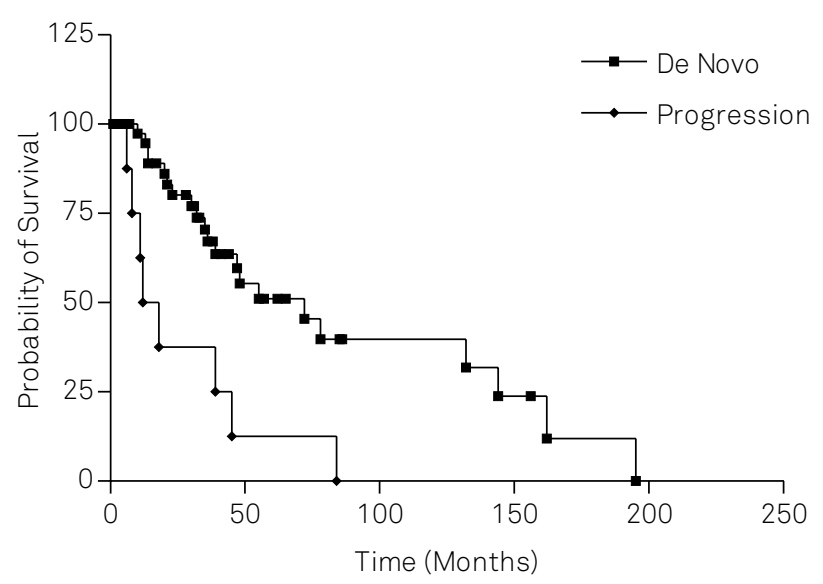

Figure 6. Recurrence-free survival curves for patients with de novo and for patients with progression meningiomas. Significant difference $(p=0.0010, d f=1$, log-rank-test.

Table 6. Preoperative, postoperative, and follow-up functional status*.

\begin{tabular}{|c|c|c|c|c|c|c|c|c|c|c|}
\hline \multirow{3}{*}{ Functional status } & \multirow{3}{*}{ KPS Score } & \multicolumn{9}{|c|}{ WHO Histopathological Grade } \\
\hline & & \multicolumn{3}{|c|}{ Preoperative } & \multicolumn{3}{|c|}{ Immediate Postoperative } & \multicolumn{3}{|c|}{ Follow-Up } \\
\hline & & Grade II & Grade III & Total & Grade II & Grade III & Total & Grade II & Grade III & Total \\
\hline No. of patients & & 43 & 09 & 52 & 43 & 09 & 52 & 39 & 08 & 47 \\
\hline $\begin{array}{l}\text { Normal/minimal symptoms } \\
\text { \& working }\end{array}$ & $80-100$ & $31(72.1 \%)$ & $06(66.7 \%)$ & $37(71.1 \%)$ & $29(67.4 \%)$ & $6(66.7 \%)$ & $35(67.3 \%)$ & $31(79.5 \%)$ & $6(66.7 \%)$ & $37(78.7 \%)$ \\
\hline Independent, not working & 70 & $12(27.9 \%)$ & $03(33.3 \%)$ & $15(28.9 \%)$ & $14(32.6 \%)$ & $2(22.2 \%)$ & $16(30.8 \%)$ & $08(20.5 \%)$ & $2(22.2 \%)$ & $10(21.3 \%)$ \\
\hline Moderate or severe disability & $<70$ & & & & & $1(11.1 \%)$ & $1(1.9 \%)$ & & & \\
\hline
\end{tabular}

KPS: Karnofsky Preformance Scale; WHO: World Health Organization.

\section{DISCUSSION}

\section{Epidemiology}

The wide range in the relative frequency of atypical (3.6 and $7.5 \%$ ) and anaplastic meningiomas ( 0.4 to $2.8 \%)^{1,2,3,5,8,9,10,11 \text {, }}$ can be explained by variable pathological criteria for their classification. However, the use of the WHO criteria improved comparisons among more recent series. We found $8.2 \%$ of patients with grade II and $1.7 \%$ with grade III ( $10 \%$ of the patients with meningiomas surgically treated), data similar to the recent series. Benign meningiomas predominates in patients of female sex; in contrast, gender distribution has been reported similar or even with male predominance among patients with Grades II/III ${ }^{2,8,12,13,14,15}$. Our results kept this tendency for patients with grade II and III tumor. Atypical meningiomas have been reported to occur after cranial irradiation for other tumors or conditions ${ }^{16,17}$. We observed two patients (3.8\%) with radiation-induced grade II (atypical) meningiomas.

\section{Histopathological features}

Several histopathological classifications were proposed for more aggressive meningiomas ${ }^{2,18}$, however, these classifications are potentially subjective. Perry et al. ${ }^{19,20}$, elaborated a simple and reproducible grading scheme for meningiomas
(The Mayo Clinic Scheme), based primarily on histological features in patients who underwent total resection. They defined the following criteria for the diagnosis of 1) atypical meningiomas: ( $\geq 4$ mitoses $/ 10 \mathrm{HPF}, \geq 2.5 / \mathrm{mm} 2$ ) or at least three of the following features: sheeting, macronuclei, small cell formation, hypercellularity ( $\geq 53$ nuclei/HPF, $\geq 118 / \mathrm{mm} 2$ ), and brain invasion; 2 ) anaplastic meningiomas ( $\geq 20$ mitotic figures/10 HPF, $\geq 12.5 \mathrm{~mm} 2$ ), or focal or diffuse loss of meningothelial differentiation (carcinoma-, sarcoma-, or melanoma-like appearance).

The WHO classifications ${ }^{1,7}$ incorporated the Mayo Clinic criteria for grading atypical and anaplastic meningiomas (proliferation index, brain invasion and mitotic activity), and emphasized more strict and objectives histological criteria. Grade II tumors included atypical tumors with three or more of the following features: increased mitotic activity ( $\geq 4$ mitoses/10 HPF), increased cellularity, small cells with a high nuclear:cytoplasmic ratio, prominent nucleoli, uninterrupted patternless or sheet-like growth, and foci of necrosis. Grade II also includes clear cell and chordoid subtypes. Grade III tumors had obvious malignant cytology resembling that of carcinoma, melanoma or high-grade sarcoma or a markedly elevated mitotic index ( $\geq 20$ mitoses $/ 10 \mathrm{HPF}$ ). Grade III also includes rhabdoid and papillary subtypes. 
Histopathological progression of meningiomas from Grade I to II and from Grade II to III has been reported in 0.16 to $2 \%$ of cases $^{8,13,15,18,19,21}$. We found 9 patients ( $1.7 \%$ of all meningiomas and $17.3 \%$ of Grades II and III meningiomas) that had tumor progression at time of their recurrence. All patients progressing from Grade I to II had focal atypia in the first biopsy slides not considered sufficient to classify them initially as atypical. This observation should be considered at least as an alert: patients with Grade I meningiomas with focal atypia deserve close follow-up imaging looking for recurrence.

Some authors postulated that genetic changes in meningiomas progress stepwise, from grade I to III ${ }^{1,22,23}$. This is supported by histopathological progression of benign meningioma at recurrence ${ }^{11}$. However, other authors ${ }^{15}$ genetic changes in tumor cells already present in the biopsies of benign recurrent progressing tumors, a finding inconsistent with the stepwise progression.

\section{Prognostic factors}

In addition to the histopathological features, several other factors were reported to influence the prognosis of the patients with atypical and anaplastic meningiomas. Age at diagnosis is a recognized prognostic factor for patients with intracranial tumors, including grades II and III meningiomas $80,12,14,19$. Among our patients, age $<60$-years-old was also a prognostic factor for overall survival, but not for RFS. Although some authors report that female sex is an unfavorable prognostic factor ${ }^{2}$, more evidence indicates that gender does not influence prognosis of patients with grades II and III meningiomas ${ }^{10,12,13,14}$, including our results. Some authors ${ }^{21}$ found that patients with Grade II tumors progressing to Grade III have shorter overall survival than patients with "de novo" grade II meningioma and our results support these findings.

Extent of resection is considered a strong prognostic factor in several studies. Recurrence rate is lower for patients submitted to total (17\%) compared with subtotal $(87 \%)$ resection $^{3}$. Survival is longer in patients that had Simpson 1 resection $^{13}$, and RFS is longer in patients with total resection ${ }^{3}$. Total or subtotal resections did not influence the survival of our patients and the RFS was longer for patients with total resection only on univariate analyis.

Molecular markers were also reported to be related to prognosis. Poor prognosis may be associated with a high MIB-1 labeling index. However, this index ranges overlap considerably for benign, atypical, and anaplastic meningio$\operatorname{mas}^{11,19,20}$, and it is only valuable to evaluate tumors with borderline atypia. In such a case, an index of $\geq 4.2 \%$ would classify the tumor as atypical ${ }^{11,19,20}$.

\section{Surgical treatment}

Surgery is the primary treatment for atypical and anaplastic meningiomas aiming a definitive diagnosis, reducing any mass effect and alleviating symptoms. Complete resection is the goal and the involved dura mater and bone should also be resected to prevent recurrence. Repeated surgery should be considered in cases where subtotal resection is required to avoid neurological deficits, such as for tumors of the cranial base and tumors with dense cortical adherence ${ }^{11}$.

\section{Radiation therapy}

\section{Conventional fractionated radiation therapy}

Results of fractionated radiation therapy for atypical and anaplastic meningiomas are difficult to evaluate because of the variation of histopathology, the small number of cases and other variables, such as extent of resection and brain invasion $^{11}$. The 5 -year survival rate for patients with atypical and anaplastic meningiomas was found to be $58 \%$ and the 5 -year RFS rate was $48 \%^{24}$, the 2 -year RFS rate was $89 \%$ for irradiated patients compared to $50 \%$ for patient not irradiated. The overall survival rate was better for patients submitted immediately to radiation therapy ${ }^{3}$. Therefore, the consensus favors fractionated radiation therapy for patients submitted to total or subtotal resection of atypical and anaplastic meningiomas ${ }^{11}$, even though this recommendation is not supported by prospective controlled trials. We find better overall survival favoring patients submitted to fractionated radiation therapy on multivariate analysis but no difference was found between the RFS curves.

\section{Stereotatic radiosurgery}

Some authors have reported good results using stereotactic radiosurgery to treat benign, atypical and anaplastic tumors, 10-year survival rates of $59 \%$ for atypical and of 59 and $0 \%$ for anaplastic meningiomas, and 5-year RFS rates of 83 and $72 \%$ for atypical and anaplastic meningiomas, respectively ${ }^{25}$. However, another report did not support these favorable results for stereotatic radiosurgery showing a very poor result for anaplastic lesions ${ }^{26}$. Tumor size is a limiting factor for stereotactic radiosurger $\mathrm{y}^{25,27}$; lesions $>3 \mathrm{~cm}$ in size do not respond to this treatment $\mathrm{t}^{25}$ and radiation necrosis occurs in $23 \%$ of the cases, with a few cases requiring surgery ${ }^{27}$.

Based on the fairly good results reported in the literature and because complications are considered uncommon ${ }^{11}$, except when radiosurgery is administered after conformal radiation therapy ${ }^{26}$, stereotactic radiosurgery probably could be administered to patients with nodular residual atypical or anaplastic meningiomas along with fractionated radiation therapy to the tumor bed, even though no prospective controlled studies support this approach ${ }^{11}$.

\section{CHEMOTHERAPY}

Anti-progesterone agents, interferon alfa-two-B, hydroxyurea and a combination of cyclophosphamide, adriamycin and 
vincristine, were used to treat unresectable benign, atypical and anaplastic meningiomas and produced tumor shrinking or stabilization in most cases in preliminary studies. The initial results were not reproduced and none of these agents has shown convincing results in the treatment of atypical and anaplastic meningiomas ${ }^{11}$.

Molecular biology suggested new options for the management of atypical and anaplastic meningiomas. Vascular Endothelium Growth Factor (VEGF) and Platelet-Derived Growth Factor (PGDF)-A and B and PDGF- $\beta$-receptor cause increased cell division and tumor proliferation ${ }^{28}$, and their expression are increased in atypical and in anaplastic meningiomas $^{29}$. Based on this knowledge, inhibitors of VEGF or VEGF receptors (vandetanib, vatalanib, bevacizumab, AEE788, and IMC-1C11), and VEGF receptor antagonists (bevacizumab and erlotinib), are available and some of them are being tested in phase II trials ${ }^{11}$.

Atypical and anaplastic meningiomas are distinct entities with poorer prognosis than benign meningiomas when treated with the current therapeutic options. Objective classification systems to grade meningiomas, which were improved by the Mayo Clinic scheme followed by the WHO grading system, which was based on the former, allow better comparison between different series. The algorithm for treatment of atypical and anaplastic meningiomas proposed by Perry et al. ${ }^{20}$, and modified by Modha \& Gutin ${ }^{11}$ is a reasonable option for treating these patients (Figure 7).

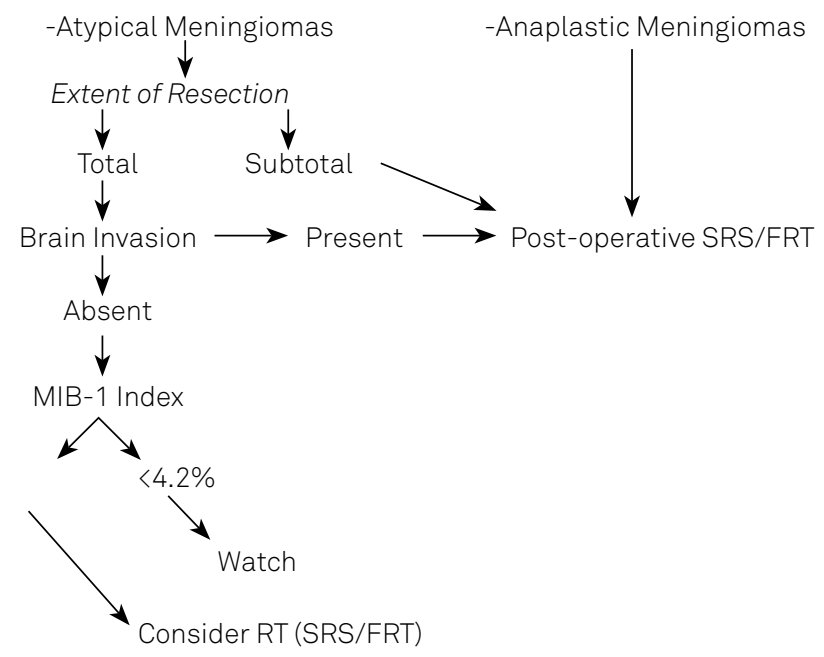

Figure 7. Algorithm for treatment of atypical and anaplastic meningiomas. Adapted from Modha \& Gutin, $2005^{14}$.

RT - radiation therapy; SRS - stereotactic radiosurgery; FRT - fractionated radiation therapy.

In conclusion, in this study we found that age under sixty-years old, grade II tumors, de novo meningiomas and total resection were main predictors for better prognosis factors among patients with atypical and anaplastic meningiomas. The treatment of atypical and anaplastic meningiomas remains a challenge for neurosurgeons, and new strategies should be developed to reduce recurrence and improve the prognosis of patients harboring these tumors.

\section{References}

1. Louis DN, Scheithauer BW, Budka H, von Deimling A, Kepes JJ. Meningiomas. In: Kleihues P, Cavenee WK, eds. World Health Organization Classification of tumours Pathology and genetics of tumours of the nervous system. Lyon: IARC; 2000. p. 175-84.

2. Mahmood A, Caccamo DV, Tomecek FJ, Malik GM. Atypical and malignant meningiomas: a clinicopathological review. Neurosurgery. 1993;33(6):955-63. doi:10.1227/00006123-199312000-00001

3. Dziuk TW, Woo S, Butler EB, Thornby J, Grossman R, Dennis WS, et al. Malignant meningioma: an indication for initial aggressive surgery and adjuvant radiotherapy. J Neurooncol. 1998;37(2):177-88. doi:10.1023/A:1005853720926

4. Cushing $\mathrm{H}$, Eisenhardt L. Meningiomas: their classification, regional behaviour, life history, and surgical results. Springfield: Charles C. Thomas; 1938.

5. Pourel N, Auque J, Bracard S, Hoffstetter S, Luporsi E, Vignaud $\mathrm{JM}$ et al. Efficacy of external fractionated radiation therapy in the treatment of meningiomas: a 20-year experience. Radiother Oncol. 2001;61(1):65-70. doi:10.1016/S0167-8140(01)00391-7

6. D’Arrigo B, Morello G, De Divitiis E, Cucciniello B. [Atypical meningiomas. Histopathological considerations on 13 personal cases]. Rass Neuropsichiatr. 1966;19(3):577-90. Italian.

7. Louis DN, Ohgaki H, Wiestler OD, Cavenee WK, Burger PC, Jouvet A et al. The 2007 WHO classification of tumours of the central nervous system. Acta Neuropathol. 2007;114(2):97-109. doi:10.1007/s00401-007-0243-4

8. Duntze J, Metellus P, Litre CF, Eap C, Theret E, Colin P. [Management of WHO grade II and II meningiomas: retrospective study of surgical series of 36 cases at a single institution]. Neurochirurgie. 2012;58(5):275-81. French. doi:10.1016/j.neuchi.2012.01.006

9. Kane AJ, Sughrue ME, Rutkowski MJ, Shangari G, Fang S, McDermott MW et al. Anatomic location is a risk factor for atypical and malignant meningiomas. Cancer. 2011;117(6):1272-8. doi:10.1002/cncr.25591

10. Cornelius JF, Slotty PJ, Steiger HJ, Hänggi D, Polivka M, George B. Malignant potential of skull base versus non-skull base meningiomas: clinical series of 1,663 cases. Acta Neurochir (Wien). 2013;155(3):407-13. doi:10.1007/s00701-012-1611-y

11. Modha A, Gutin PH. Diagnosis and treatment of atypical and anaplastic meningiomas: a review. Neurosurgery. 2005;57(3):538-50. doi:10.1227/01.NEU.0000170980.47582.A5

12. Rosenberg LA, Prayson RA, Lee J, Reddy C, Chao ST, Barnett GH et al. Long-term experience with World Health Organization grade III (malignant) meningiomas at a single institution. Int J Radiat Oncol Biol Phys. 2009;74(2):427-32. doi:10.1016/j.ijrobp.2008.08.018

13. Palma L, Celli P, Franco C, Cervoni L, Cantore G. Long-term prognosis for atypical and malignant meningiomas: a study of 71 surgical cases. J Neurosurg. 1997;86(5):793-800. doi:10.3171/jns.1997.86.5.0793

14. Pasquier D, Bijmolt S, Veninga T, Rezvoy N, Villa S, Krengli M et al. Atypical and malignant meningioma: outcome and prognostic factors in 119 irradiated patients. A multicenter, retrospective study of the Rare Cancer Network. Int J Radiat Oncol Biol Phys. 2008;71(5):1388-93. doi:10.1016/j.ijrobp.2007.12.020 
15. Al-Mefty O, Kadri PA, Pravdenkova S, Sawyer JR, Stangeby C, Hussain M. Malignant progression in meningioma: documentation of a series and analysis of cytogenetic findings. J Neurosurg. 2004;101(2):210-8. doi:10.3171/jns.2004.101.2.0210

16. Hug EB, Devries A, Thornton AF, Munzenride JE, Pardo FS, Hedley-Whyte ET, et al. Management of atypical and malignant meningiomas: role of high-dose, 3D-conformal radiation therapy.J Neurooncol. 2000;48(2):151-60. doi:10.1023/A:1006434124794

17. Al-Mefty O, Topsakal C, Pravdenkova S, Sawyer JR, Harrison MJ. Radiation-induced meningiomas: clinical, pathological, cytokinetic, and cytogenetic characteristics. J Neurosurg. 2004;100(6):1002-13. doi:10.3171/jns.2004.100.6.1002

18. Jääskelainen J, Haltia M, Servo A. Atypical and anaplastic meningiomas: radiology, surgery, radiotherapy, and outcome. Surg Neurol. 1986;25(3):233-42. doi:10.1016/0090-3019(86)90233-8

19. Perry A, Stafford SL, Scheithauer BW, Suman VJ, Lohse CM. Meningioma grading: an analysis of histologic parameters. Am J Surg Pathol. 1997;21(12):1455-65. doi:10.1097/00000478-199712000-00008

20. Perry A, Scheithauer BW, Stafford SL, Lohse CM. "Malignancy" in meningiomas: a clinicopathologic study of 116 patients with grading implications. Cancer. 1999;85(9):2046-56. doi:10.1002/(SICI)10970142(19990501)85:9<2046::AID-CNCR23>3.0.C0;2-M

21. Krayenbühl N, Pravdenkova S, Al-Mefty O. De novo versus transformed atypical and anaplastic meningiomas: comparisons of clinical course, cytogenetics, cytokinetics, and outcome.. Neurosurgery. 2007;61(3):495-503. doi:10.1227/01.NEU.0000290895.92695.22

22. Boström J, Meyer-Puttlitz B, Wolter M, Blaschke B, Weber RG, Lichter $P$ et al. Alterations of the tumor suppressor genes CDKN2A (p16(INK4a), p14(ARF)), CDKN2B (p15(INK4b)), and CDKN2C
(p18(INK4C)) in atypical and anaplastic meningiomas. Am J Pathol. 2001;159(2):661-9. doi:10.1016/S0002-9440(10)61737-3

23. Perry A, Banerjee R, Lohse CM, Kleinschmidt-DeMasters BK, Scheithauer BW. A role for chromosome 9p21 deletions in the malignant progression of meningiomas and the prognosis of anaplastic meningiomas. Brain Pathol. 2002;12(2):183-90. doi:10.1111/j.1750-3639.2002.tb00433.x

24. Goldsmith BJ, Wara WM, Wilson CB, Larson DA. Postoperative irradiation for subtotally resected meningiomas. A retrospective analysis of 140 patients treated from 1967 to 1990. J Neurosurg. 1994;80(2):195-201. doi:10.3171/jns.1994.80.2.0195

25. Kondziolka D, Levy El, Niranjan A, Flickinger JC, Lunsford LD. Long-term outcomes after meningioma radiosurgery: physician and patient perspectives. J Neurosurg. 1999;91(1):44-50. doi:10.3171/jns.1999.91.1.0044

26. Stafford SL, Pollock BE, Foote RL, Link MJ, Gorman DA, Schomberg PJ et al. Meningioma radiosurgery: tumor control, outcomes, and complications among 190 consecutive patients. Neurosurgery. 2001;49(5):1029-37.

27. Ojemann, SG, Sneed PK, Lardon DA, Gutin PH, Berger MS, Verhey $L$ et al. Radiosurgery for malignant meningioma: results in 22 patients. J Neurosurg. 2000;93 Suppl 3:62-7.

28. Johnson MD, Woodard A, Kim P, Frexes-Steed M. Evidence for mitogen-associated protein kinase activation and transduction of mitogenic signals by platelet-derived growth factor in human meningioma cells. J Neurosurg. 2001;94(2):293-300. doi:10.3171/jns.2001.94.2.0293

29. Lamszus K. Meningioma pathology, genetics, and biology.J Neuropathol Exp Neurol. 2004;63(4):275-86. 